\title{
Ictal pain: occurrence, clinical features, and underlying etiologies.
}

\author{
Ali Akbar Asadi-Pooya \\ Thomas Jefferson University \\ Marjan Asadollahi \\ Thomas Jefferson University \\ Michael R. Sperling \\ Thomas Jefferson University
}

Follow this and additional works at: https://jdc.jefferson.edu/neurologyfp

Part of the Neurology Commons

Let us know how access to this document benefits you

\section{Recommended Citation}

Asadi-Pooya, Ali Akbar; Asadollahi, Marjan; and Sperling, Michael R., "Ictal pain: occurrence, clinical features, and underlying etiologies." (2016). Department of Neurology Faculty Papers. Paper 119.

https://jdc.jefferson.edu/neurologyfp/119

This Article is brought to you for free and open access by the Jefferson Digital Commons. The Jefferson Digital Commons is a service of Thomas Jefferson University's Center for Teaching and Learning (CTL). The Commons is a showcase for Jefferson books and journals, peer-reviewed scholarly publications, unique historical collections from the University archives, and teaching tools. The Jefferson Digital Commons allows researchers and interested readers anywhere in the world to learn about and keep up to date with Jefferson scholarship. This article has been accepted for inclusion in Department of Neurology Faculty Papers by an authorized administrator of the Jefferson Digital Commons. For more information, please contact: JeffersonDigitalCommons@jefferson.edu. 
Title: Ictal pain

Authors: Ali A. Asadi-Pooya, M.D., Marjan Asadollahi, M.D., Michael R. Sperling, M.D.

Jefferson Comprehensive Epilepsy Center, Department of Neurology, Thomas Jefferson University, Philadelphia, Pennsylvania, USA.

Address for correspondence:

Ali A. Asadi-Pooya, M.D.

Department of Neurology

901 Walnut Street, Suite 435

Philadelphia, PA 19107

Phone: 215-955-1222

Fax: 215-955-3745

E-mail: aliasadipooya@yahoo.com; marjan.asadollahi@jefferson.edu;

michael.sperling@jefferson.edu

Running title: Ictal pain

Key words: Epilepsy; Ictal; Pain; Psychogenic; Seizure

Number of characters in the title: 11 ; Number of characters in the running head: 11 ; Number of text pages: 5; number of words: 1556; number of words in the abstract: 206; number of references: 8; number of figures: 0 ; number of tables: 1 . 


\begin{abstract}
Purpose: We described a series of patients with ictal pain to estimate its occurrence and characterize the underlying etiology.

Methods: We retrospectively reviewed all the long-term video-EEG reports from Jefferson Comprehensive Epilepsy Center over a 12-year period (2004-2015) for the occurrence of the term "pain" in the text body. All the extracted reports were reviewed and patients with at least one documented episode of ictal pain in epilepsy monitoring unit (EMU) were included in the study.
\end{abstract}

Results: During the study period, 5133 patients were investigated in our EMU. Forty-six patients $(0.9 \%)$ had at least one documented episode of ictal pain. Twenty-four patients $(0.5 \%)$ had psychogenic nonepileptic seizures (PNES), 10 patients $(0.2 \%)$ had epilepsy, 11 patients $(0.2 \%)$ had migraine, and one woman had a cardiac problem. Pain location was in upper or lower extremities (with or without other locations) in $80 \%$ of the patients with epilepsy, $33 \%$ of the patients with PNES ( $\mathrm{p}=0.01)$, and none of the patients with migraine.

Conclusion: Ictal pain is a rare finding among patients evaluated in epilepsy monitoring units. PNES are the most common cause, but ictal pain is not specific for this diagnosis. Location of the ictal pain in a limb may help differentiate an epileptic cause from others. 


\section{Introduction}

Pain as an aura or a symptom of epileptic seizures has been infrequently described in the literature. The reported frequency of epileptic ictal pains ranges from $0.2 \%$ to $2.8 \%[1,2]$. This symptom can be experienced anywhere in the body. Gowers, first described pain occurring with seizures in 1901. He described three varieties: hemicorporeal (unilateral), cephalic and abdominal (visceral or pneumogastric) [2]. Unilateral pain is probably due to involvement of the contralateral primary somatosensory cortex. The mechanism of ictal headache and abdominal ictal pain remains unclear [2]. In this study, we describe a series of patients with ictal pain to estimate its occurrence and characterize the underlying etiology. We aim to investigate whether ictal pain offers a significant value to determine the clinical diagnosis.

\section{Methods}

We retrospectively reviewed all the long-term video-EEG reports from Jefferson Comprehensive Epilepsy Center over a 12-year period (2004-2015) for the occurrence of the term "pain" in the text body. All the extracted reports were reviewed and patients with at least one episode of documented ictal pain in epilepsy monitoring unit (EMU) were included in the study. For each included patient, the data were reviewed from the electronic medical records, EMU report, and neuroimaging records. Chi-Square, t- test, and Kolmogorov-Smirnov test were used for statistical analyses. P value less than 0.05 was considered significant. This study was conducted with approval by Thomas Jefferson University Institutional Review Board. 


\section{Results}

During the study period, 5133 patients were investigated in our EMU. Forty-six patients $(0.9 \%)$ had at least one episode of documented ictal pain. Twenty-four patients $(0.5 \%)(15$ women and nine men) had psychogenic nonepileptic seizures (PNES), 10 patients (0.2\%) (eight women and two men) had epilepsy, 11 patients $(0.2 \%)$ (nine women and two men) had migraine, and one woman had a cardiac problem (i.e., atrial tachycardia) with brief episodes of chest pain. All patients with PNES had at least one habitual seizure recorded in our EMU. The electroencephalography (EEG) was normal during and after these events. No further testing was required for these patients. Patients with PNES described pain during their seizures in their head (12 patients; 50\%), limb (eight patients; 33.3\%), abdomen (three patients; $12.5 \%$ ), chest (three patients; $12.5 \%$ ), and face (two patients; $8.3 \%$ ). Five patients $(20.8 \%)$ had multiple pain locations and the rest had a single pain location. All patients with epilepsy had at least one habitual seizure recorded in our EMU. Eight patients (80\%) reported pain in their limbs and three patients $(30 \%)$ had headache during their seizures; one patient had both headache and limb pain. The EEG recordings, brain magnetic resonance imaging (MRI) findings, diagnosis, treatment plan, and outcome in these patients are explained in Table 1. Sex ratio was not significantly different between the groups $(\mathrm{p}=0.3)$. Age at onset was not significantly different between patients with epilepsy (29.5 \pm 16 years) and those with PNES (28.9 \pm 14 years) or migraine (39.9 \pm 12 years) $(\mathrm{p}=0.2)$. Pain location was in upper or lower extremities (with or without other locations) in $80 \%$ of the patients with epilepsy and $33 \%$ of the patients with PNES $(p=0.01)$. None of the patients with migraine reported pain in their limbs. Three patients (30\%) with epilepsy and 12 patients $(50 \%)$ with PNES reported ictal headache $(\mathrm{p}=0.2)$. None of the patients with epilepsy, three patients (12.5\%) with PNES, and one patient (9\%) with migraine reported 
abdominal pain with their ictal episodes $(p=0.5)$. Videos were not available for most of the patients to be reviewed.

\section{Discussion}

Ictal pain is a rare finding among patients evaluated in epilepsy monitoring units. The frequency of ictal pain at our center was $0.9 \%$ and the frequency of epileptic ictal pain was $0.2 \%$, which is consistent with a previous study [1]. The most common underlying etiology for ictal pain in our study was PNES. However, epilepsy and migraine were also associated with this symptom. This is an important consideration while dealing with this rare symptom in patients suspected of having epilepsy. Although, ictal pain is not a specific or pathognomonic sign for PNES, its presence should raise suspicion for PNES, which is common among these patients. Location of the ictal pain may help differentiate patients with epilepsy from others. Peripheral pain in extremities favors a diagnosis of epilepsy rather than the other diagnoses. Ictal headache or abdominal pains are not helpful in differentiating patients with epilepsy from PNES or migraine. Admission at a specialized center with expertise in diagnosing these conditions with video-EEG monitoring can settle the diagnosis in affected patients.

Among our patients with epileptic ictal pain, all had definite or probable focal epilepsy. Four of our patients had pain during focal seizures with unilateral or asymmetric tonic posturing and others reported pain with their simple partial seizures. Pain during focal seizures with muscle contraction (i.e., tonic seizures) is not necessarily an ictal phenomenon and could be a reaction to the severe muscle spasm. These often arise from frontal lobes; three out of four patients with focal seizures and unilateral or asymmetric tonic posturing in our series had either EEG or MRI 
findings suggesting frontal lobe epilepsy. We cannot comment on the localization of the epileptic focus in our patients with simple partial seizures as interictal and ictal EEGs were not well localizing. The underlying etiology of epilepsy, based on the imaging findings, was variable in our patients and epileptic ictal pain was not specific to any etiology or location. However, we can conclude that epileptic pain, particularly peripheral limb pain, is a rare type of partial seizure in patients with focal epilepsy. This is concordant with most previous reports [1, 2]. We did not have EEG localization for most seizures to evaluate the localizing and lateralizing value of the epileptic ictal pain. However, in a previous study, the authors observed that in all patients with painful unilateral seizures, the site of seizure origin could be lateralized to the cerebral hemisphere contralateral to the pain [2]. These seizures have been reported to arise from either parietal or frontal lobes [2].

Epileptic ictal headache has usually been described with focal and rarely with generalized epilepsy syndromes [3-5]. Seizure-related headaches have been categorized depending on the time that headache occurs in relation to the epileptic seizure. When a headache precedes the seizure, it is called a pre-ictal headache. Epileptic ictal headaches are headaches that occur in close proximity to the seizure's expression and are a primary manifestation of the seizure. These are not common. Headaches occurring directly after the ictal phenomena are called post-ictal headaches. These latter headaches are the most common type of seizure-related headaches [6]. In one study [7], to determine the lateralizing value of peri-ictal headache, the authors conducted a standardized interview of 100 patients with focal epilepsy; 60 with temporal lobe epilepsy (TLE) and 40 with extratemporal epilepsy. Peri-ictal headache occurred in 47 of 100 (47\%) patients. Peri-ictal headache was more likely to be ipsilateral to the seizure onset in TLE (90\%) than in 
those with extratemporal epilepsy $(12 \% ; \mathrm{p}<0.001)$. The mechanism of peri-ictal headache remains unclear [7].

None of our patients reported abdominal pain with their epileptic seizures. Epileptic abdominal pain is a rare symptom which often points to a temporal lobe origin for the seizures in adult patients [2]. Abdominal epilepsy is characterized by paroxysmal episodes of abdominal pain, a variety of other abdominal complaints, electroencephalographic abnormalities, and a good response to antiepileptic drugs [8]. This condition has been reported mainly in children and young adolescents $[2,8]$. In children, it has been associated with either generalized or focal epilepsy syndromes $[2,8]$. The mechanism of epileptic abdominal pain remains unclear.

The limitations of our study include its retrospective design and single institution nature. The patients in this study do not represent the general population of patients with epilepsy and other differential diagnoses. No prospective study has ever looked for this semiological manifestation in the general population of patients with epilepsy. However, given the rarity of this semiological manifestation (i.e., ictal pain), prospective studies are probably not feasible. In addition, the very large sample size in our study provides value in clinical practice to help determine the diagnosis in patients reporting this symptom. There is a potential for sampling bias due to the limited search terms used for identifying ictal pain. We did not have access to many of the videos to verify the findings (e.g., duration of the seizures, characteristics of the seizures, etc.) ourselves, but all the videos were reviewed by board certified epileptologists working at this institution. 


\section{Conclusion}

We add to the literature on ictal pain by providing additional information on its differential diagnosis, frequency, and etiology. Ictal pain is a rare finding among patients evaluated in EMUs. The most common underlying etiology for ictal pain is PNES; however, it is not a specific or pathognomonic sign for PNES. Location of the ictal pain in a limb may help differentiate patients with epilepsy from others. Epileptic ictal pain is a rare symptom of partial seizures in patients with focal epilepsy.

\section{Conflict of interest}

Ali A. Asadi-Pooya, M.D. and Marjan Asadollahi, M.D. report no disclosures.

Michael R. Sperling, M.D., Research: contracts with Thomas Jefferson University with Dr,. Sperling as PI with: Eisai, UCB Pharma, Sunovion, SK Life Sciences, Marinus, Lundbeck, Medtronics, Accorda, Upsher-Smith, Brain Sentinel, Pfizer, Glaxo.

\section{Acknowledgment}

This was a non-funded study. 


\section{References}

1. Kuloğlu Pazarcı N, Bebek N, Baykan B, Gürses C, Gökyiğit A. Reappraisal of epileptic pain as a rare symptom of seizures. Epilepsy Behav 2016; 55: 101-107.

2. Young GB, Blume WT. Painful epileptic seizures. Brain 1983; 106 (Pt 3): 537-554.

3. Fanella M, Fattouch J, Casciato S, et al. Ictal epileptic headache as "subtle" symptom in generalized idiopathic epilepsy. Epilepsia 2012; 53(4): e67-70.

4. Dainese F, Mai R, Francione S, Mainardi F, Zanchin G, Paladin F. Ictal headache: headache as first ictal symptom in focal epilepsy. Epilepsy Behav 2011; 22(4): 790-792.

5. Parisi P, Striano P, Verrotti A, Villa MP, Belcastro V. What have we learned about ictal epileptic headache? A review of well-documented cases. Seizure 2013; 22(4): 253-258.

6. Saitowitz Z, Flamini R, Berenson F. Ictal epileptic headache: a review of current literature and differentiation from migralepsy and other epilepsies. Headache 2014; 54(9): 1534-1540.

7. Bernasconi A, Andermann F, Bernasconi N, Reutens DC, Dubeau F. Lateralizing value of peri-ictal headache: a study of 100 patients with partial epilepsy. Neurology $2001 ; 56$ : $130-132$.

8. Mondal R, Sarkar S, Bag T, Mondal K, Saren A. A pediatric case series of abdominal epilepsy. World J Pediatr 2014; 10(1): 80-82. 